\title{
Shear Bond Strength of Three Porcelain Repair Systems on Porcelain in Dry and Aged Conditions
}

\section{Gülce Subaşı* and Özgür İnan}

Department of Prosthodontics, Faculty of Dentistry, Selcuk University, Konya, Turkey

\begin{abstract}
Objective: This study compared the durability of bond strength of a resin composite to feldspathic ceramic by using three porcelain repair systems.
\end{abstract}

Methods: Sixty ceramic blocks (Vitablocks Mark II) were divided into three groups, according to the repair method (CO [Cojet repair kit], CL [Clearfil repair kit], and UL [Ultradent repair kit]). Composite resin was photo-polymerized on each ceramic. Half of the specimens were submitted to the shear bond strength test after 24 hours of water storage or thermal cycling. The bond strength data was analyzed by Weibull analysis and Wald tests $(p=0.05)$.

Results: The characteristic bond strength values $\left(\sigma_{0}\right)$ of repair systems in dry conditions were $5.823,6.512$ and 6,867 MPa and after aging conditions these were 4.112, 3.935 and 4.210 MPa for CO, CL and UL, respectively. Wald test results revealed that there were significant differences among groups in characteristic bond strength $\left(\sigma_{0}\right)$ $(p<0.001)$.

Conclusion: Thermal cycling had a significant effect on the bond strength of three repair kits and bond strength results decreased after thermal cycling.

Keywords: Bond strength; Porcelain repair systems; Thermal cycling

\section{Introduction}

Increased patient demand for aesthetic and metal-free restorations has resulted in the progress of all-ceramic restorations. All-ceramic restorations can be created in many ways using different materials. Computer-aided design and manufacturing (CAD/CAM) systems have dramatically enhanced dentistry by providing high-quality restorations [1].

Vita Mark II (VITA Zahnfabrik, Bad Sackingen, Germany) is a machinable feldspathic porcelain that was introduced in 1991 for the CEREC 1 (Siemens AG, Bensheim, Germany) system [2]. It can be used in inlays, onlays, veneers, and anterior crowns [1,2]. Bindl and Mörmann [3] reported that clinically bonded Mark II CAD/CAMgenerated partial crowns had shown excellent results up to 5 years after placement. They [4] also evaluated the survival analysis of CAD/ CAM-generated monoceramic Mark II crowns for fracture over a period of 2-5 years. The cumulative survival rate regarding fracture of the crown was $94.4 \%$ for Mark II monoceramic crowns. Although these restorations demonstrate aesthetic results, they are susceptible to fractures. Previous clinical studies on glass-ceramic inlays, or laminates $[5,6]$, reported chippings of the veneering ceramics. Since such ceramics are cemented adhesively, their removal for indirect repairs without creating any damage either to tooth structure or to the restoration itself is difficult. In addition, cost of the treatment can prevent renewal of the restoration. Therefore, depending on the size of the fracture in the veneering material, intraoral repair methods using resin composites and adequate surface treatments may be indicated $[7,8]$.

The clinical success of the porcelain repair systems depends on the integrity of the bond between porcelain and resin composite. The bond is achieved either by chemical or mechanical methods. Due to insufficient bonding characteristics of the chemical agents, the porcelain surfaces must be physically altered when these agents are used.

Various methods have been reported to repair fractured porcelain with composite. These methods include sandblasting with aluminum oxide $\left(\mathrm{Al}_{2} \mathrm{O}_{3}\right)$ particles, roughening with a diamond bur, etching porcelain surfaces with hydrofluoric acid or acidulated phosphate fluoride gel, and a tribochemically silica-coating system. These methods create micro-mechanical retention on the porcelain surfaces [7-9]. Chemical retention can be provided by using silane-coupling agents $[10,11]$. Silane-coupling agents can be used in combination with the previous surface alteration methods $[7,9,12,13]$. Silane is a dual functional monomer consisting of a silanol group that reacts with the ceramic surface and contains a methacrylate group that co-polymerizes with the resin matrix of the composite. The specific silane typically used in dentistry for both intraoral repair and treatment of ceramic restorations before placement is 3-methacryloxypropyltrimethoxysilane $(\gamma$-MPS) $[10,11]$.

The purpose of this in vitro study was to compare the shear bond strength of composite resin that had been bonded to a feldspathic porcelain in dry and aged conditions by using three commercially different porcelain repair systems. The tested null hypothesis was that the repair bond strength would decrease after aging conditions.

\section{Materials and Methods}

\section{Specimen preparation}

The materials used in this study are presented in Table 1. Sixty blocks of feldspathic ceramic (Vita Blocs Mark II) (12 mm x $10 \mathrm{~mm}$ x $2 \mathrm{~mm}$ ) were prepared using a slow-speed diamond saw (Isomet 1000

*Corresponding author: Gülce Subaşı, Department of Prosthodontics, Faculty of Dentistry, Selcuk University, Konya, Turkey, Tel: +903322231186; Fax +903322410062; E-mail: gulce2subasi@yahoo.co.uk

Received October 26, 2011; Accepted January 30, 2012; Published February 02, 2012

Citation: Subaşı G, İnan Ö (2012) Shear Bond Strength of Three Porcelain Repair Systems on Porcelain in Dry and Aged Conditions. Dentistry 2:119. doi:10.4172/2161-1122.1000119

Copyright: ( 2012 Subaşı G, et al. This is an open-access article distributed under the terms of the Creative Commons Attribution License, which permits unrestricted use, distribution, and reproduction in any medium, provided the original author and source are credited. 
Precision Saw; Buehler Ltd, Lake Bluff, Illinois, USA) under watercooling. The ceramic surfaces were polished with 1000-grit silicon carbide paper under water-cooling and then ultrasonically cleaned (BioSonic JR; Whaledent, New Jersey, USA) in distilled water for 5 minutes. Ceramic specimens were embedded in self-cure acrylic resin (Meliodent; Heraeus Kulzer, Hanau, Germany), leaving one surface of the porcelain uncovered. Samples were then randomly divided into 3 groups $(n=20)$, depending on the repair method to be employed. In all groups, repair methods were constructed according to the manufacturer's instructions.

\section{Repair methods}

Cojet Repair Kit (CO): Ceramic surfaces were air-abraded using an intraoral device (Cojet) that was filled with $30-\mu \mathrm{m}$ alumina particles coated with silica (Cojet Sand) from a distance of approximately $10 \mathrm{~mm}$ and at a pressure of 3 bar for 15 seconds. Following surface conditioning, the sand particle remnants were gently air blown. The conditioned surfaces were then coated with $\gamma$-MPS silane (Espe Sil), rested for 5 minutes, and air-dried. Then, an adhesive resin (Visio Bond) was applied using a microbrush, and was air thinned and photopolymerized for 20 seconds.

Clearfil Repair (CL): The ceramic surfaces were air-abraded with the same device (Cojet) that was filled with $50-\mu \mathrm{m} \mathrm{Al}_{2} \mathrm{O}_{3}$ particles (Korox, Bego, Bremen, Germany) from a distance of approximately 10 $\mathrm{mm}$ at a pressure of 3 bar for 15 seconds. Forty percent phosphoric acid $\left(\mathrm{H}_{3} \mathrm{PO}_{4}\right)$ (K-Etchant $\left.\mathrm{Gel}\right)$ was applied to the surface for 5 seconds, rinsed, and dried thoroughly. Clearfil SE Bond Primer and Clearfil
Porcelain Bond Activator were mixed at a 1:1 ratio, waited for 5 seconds, and then applied on the ceramic surface for 5 seconds and air thinned.

Ultradent (UL): The same porcelain-conditioning procedure as the CL group was applied to this group. Thereafter, the porcelain surfaces were etched with $9 \%$ buffered hydrofluoric acid (HF) (Ultradent Porcelain Etch) for 1 minute. The acid neutralizer (EtchArrest) was blended into the etchant until the yellow color of the etchant was no longer seen. They were then rinsed with water and dried with air. A silane agent (Ultradent Silane) was applied to the ceramic surface for 60 seconds, evaporated for 1 minute, and dried with air. Thereafter, a puddle coat of bonding resin (PQ1 resin) was firmly scrubbed into the silanated porcelain surface. Resin was thinned with light application of dry air to the point of losing milky appearance, then light cured for 20 seconds.

In all groups, composite resin (Filtek Z250) was used for repairing the porcelain surfaces. Composite resin was packed with a hand instrument to the treated porcelain surfaces by using a special mould, which had a radius of $5 \mathrm{~mm}$ and a height of $2 \mathrm{~mm}$. Composite resin was light polymerized for 40 seconds. A bluephase light-curing unit (Ivoclar; Vivadent, Schaan, Liechstein) was used at a distance of $0 \mathrm{~mm}$ with an intensity of $450 \mathrm{~mW} / \mathrm{cm}^{2}$. The ceramic-composite repairedspecimens groups were then randomly divided into two subgroups according to the storage conditions.

\section{Storage conditions}

Non-thermal cycling (NTC): In this group, the specimens were

\begin{tabular}{|c|c|c|c|}
\hline Brand & Manufacturer & Chemical composition & $\begin{array}{l}\text { Batch } \\
\text { Number }\end{array}$ \\
\hline $\begin{array}{l}\text { VITABLOCS Mark II for } \\
\text { CEREC/inLab (2M1C I12) }\end{array}$ & $\begin{array}{l}\text { VITA Zahnfabrik, Bad Säckingen, } \\
\text { Germany }\end{array}$ & $\begin{array}{l}\text { Mixture of feldspathic crystalline particles embedded in a glassy matrix Vol \% } \\
\qquad 30\end{array}$ & 15670 \\
\hline \multicolumn{4}{|l|}{ Cojet Repair Kit (CO) } \\
\hline CoJet Sand & 3M ESPE AG, Seefeld, Germany & Aluminum trioxide particles coated with silica, particles size $30 \mu \mathrm{m}$. & 359747 \\
\hline ESPE-Sil & 3M ESPE AG, Seefeld, Germany & 3-MPS silane (3-methacryloyloxypropyltrimethoxy silane), ethanol & 381242 \\
\hline Visio Bond & 3M ESPE AG, Seefeld, Germany & $\begin{array}{l}\text { Bisacrylate, aminodiol methacrylate, camphor quinone, benzyl dimethyl ketale, } \\
\text { stabilizers }\end{array}$ & 302239 \\
\hline \multicolumn{4}{|l|}{ Clearfill Repair Kit (CL) } \\
\hline K-Etchant Gel & Kuraray Medical Inc, Okayama, Japan & $40 \% \mathrm{H}_{3} \mathrm{PO}_{4}$ & 00462B \\
\hline Clerafill SE Bond Primer & Kuraray Medical Inc, Okayama, Japan & $\begin{array}{l}\text { HEMA, water, hydrophilic dimethacylate,10-methacryloyloxydecyl dihydrogen } \\
\text { phosphate (MDP), camphorquinone, tetriary amine }\end{array}$ & 00942A \\
\hline $\begin{array}{l}\text { Clearfill Porcelain Bond } \\
\text { Activator }\end{array}$ & Kuraray Medical Inc, Okayama, Japan & $\begin{array}{l}\text { BisphenolA polyethoxydimethacrylate, 3-methacryloyloxypropyltrimethoxy } \\
\text { silane. }\end{array}$ & $00241 \mathrm{~A}$ \\
\hline \multicolumn{4}{|l|}{ Ultradent Repair Kit (UL) } \\
\hline Ultradent Porcelain Etch & Ultradent Products Inc, USA & $\% 9$ buffered HF acid & C101 \\
\hline EtchArrest & Ultradent Products Inc, USA & Calcium carbonate $\% 4.5$, sodium bicarbonate $\% \sim 10$ & W051 \\
\hline Ultradent Silane & Ultradent Products Inc, USA & Methacryloxy propyl trimethoxy silane \%15, Isopropyl alcohol \%92 & 0091 \\
\hline $\begin{array}{l}\text { PQ1 Single syringe bonding } \\
\text { agent }\end{array}$ & Ultradent Products Inc, USA & $\begin{array}{l}\text { Light cured bonding agent with ethyl alcohol solvent carrier. PQ1 is } 40 \% \text { filled } \\
\text { and contains FluorUtite }{ }^{\mathrm{TM}} \text {, nature's high fluoride sustained release mineral. }\end{array}$ & X091 \\
\hline Filtek Z250 (shade C2) & 3M ESPE, St Paul, Minn., U.S.A. & $\begin{array}{l}\text { Bisphenol A diglycidylmethacrylate (BIS-GMA), urethane dimethacrylate } \\
\text { (UDMA) and ethoxylated bisphenol A glycol dimethacrylate (Bis-EMA) resins }\end{array}$ & 7WA \\
\hline
\end{tabular}

Table 1: Materials used in this study. 
submitted to the shear test after being stored in distilled water at $37^{\circ} \mathrm{C}$ for 24 hours.

Thermal cycling (TC): The specimens were stored in distilled water at $37^{\circ} \mathrm{C}$ for 24 hours and then submitted to the thermal cycling (5000 cycles, between $5^{\circ} \mathrm{C}$ and $55^{\circ} \mathrm{C}$, with a dwell time of 20 seconds at each temperature, and a transfer time from one bath to the others of 10 seconds) (Custom-made thermal cycling machine, Nova Ticaret, Konya, Turkey).

Thus, considering the repair methods ( 3 groups) and storage conditions (2 groups), 6 testing groups were obtained, yielding 10 specimens in each group $(\mathrm{n}=10)$.

\section{Shear bond strength test}

Shear testing of all groups was performed on a universal testing machine (TSTM 02500; Elista Ltd., Istanbul, Turkey) at a crosshead speed of $0.5 \mathrm{~mm} / \mathrm{min}$. A knife-edge blade apparatus was used to direct a parallel shearing force as close as possible to the interface of the ceramic and the composite cylinder. The shear debonding forces were recorded in $\mathrm{N}$. The failure loads $(\mathrm{N})$ were divided by the bonding areas $\left(\mathrm{mm}^{2}\right)$, and then the shear debonding forces were converted into MPa.

\section{Scanning electron microscopy (SEM) and failure type analysis}

The effects of the surface treatments and different etchants on the feldspathic porcelain surfaces were examined in a SEM (LEO 440; Zeiss, Cambridge, UK) at $1.50 \mathrm{KX}$ magnification.

After shear-bond testing, fracture surfaces of all specimens were analyzed both visually and by a stereomicroscope (Leica MZ16; Leica Microsystems, Switzerland) at 10X magnification. Failure types were categorized as adhesive between ceramic and composite (ADHES), and cohesive failure (COHES) and cohesive failure of the ceramic accompanied by adhesive failure at the interface (MIX). For failure type analysis, a specimen that demonstrated a mixed failure type was further selected for SEM at 45X magnification.

\section{Statistical analysis}

Due to the strength data of ceramic materials, which usually shows an asymmetrical distribution, the variability of the shear strength values was analyzed by using two-parameter cumulative Weibull distribution functions. The description of Weibull distribution is given in the formula [14]:

$$
\mathrm{P}(\sigma)=1-\exp \left[-\left(\sigma / \sigma_{0}\right)^{\mathrm{m}}\right],
$$

where $\mathrm{P}$ is the probability of failure, $\mathrm{r}$ is the shear strength at a given $\mathrm{P}$, $\sigma_{0}$ is the characteristic Weibull parameter at the fracture probability of $63.2 \%$, and $\mathrm{m}$ is the Weibull modulus.

The maximum likelihood method was preferable to least squares method for estimating the Weibull parameters. Wald tests and 95\% confidence intervals were used for comparisons of the scales and the location parameters of Weibull distribution. Also, the Wald test is performed for equal shapes or scales. All results were evaluated according to the 0.05 significance level.

For failure type analysis, due to the fact that the expected number of observations in some cells was less than 5 , chi-square analysis was not applied.

\section{Results}

\section{Shear bond strength results}

The Weibull analysis results were presented in Table 2 and Figure 1. Table 2 showed the Weibull analysis and Wald test results for comparisons of six groups, which included the Weibull modulus (m), characteristic strength $\left(\sigma_{0}\right)$, standard errors of $\mathrm{m}$ and $\sigma_{0} 95 \%$ confidence intervals of both $\mathrm{m}$ and $\sigma_{0}$ and the other $\sigma_{0}$ parameter. Figure 1 showed the fracture probability of the bond between the ceramic material and resin composite with different shear stress levels.

The characteristic strength $\left(\sigma_{0}\right)$ values $(\mathrm{MPa})$ and $95 \%$ confidence intervals $(\mathrm{MPa})$ of repair groups in dry and aged conditions were as follows: CO-NTC (5.823) (5.342-6.347); CO-TC (4.112) (3.810-4.438); CL-NTC (6.512) (6.020-7.043); CL-TC (3.935) (3.576-4.330); ULNTC (6.867) (6.151-7.667); UL-TC (4.210) (3.910-4.532).

Table 2 showed the Weibull statistics and Wald test results of 6 groups. According to the Wald tests, there were no significant differences among groups with related $\mathrm{m}$ parameter $(\mathrm{P}=0.871)$ However, there were significant differences among groups with related

\begin{tabular}{|c|c|c|c|c|c|c|c|c|c|}
\hline MATERIAL & $\begin{array}{l}\text { Shape } \\
(m)\end{array}$ & Std. Error & $\begin{array}{c}95 \% \mathrm{Cl} \\
(\mathrm{MPa})\end{array}$ & $\begin{array}{c}\text { Scale }\left(\sigma_{0}\right) \\
(\mathrm{MPa})\end{array}$ & Std. Error & $95 \% \mathrm{Cl}(\mathrm{MPa})$ & $\sigma 0.05$ & Mean & SD \\
\hline CO-NTC & 7.651 & 1.757 & $4.878,12.001$ & $5.823(b)$ & 0.256 & $5.342,6.347$ & 3.949 & 5.498 & 0.748 \\
\hline CO-TC & 8.579 & 2.154 & $5.244,14.036$ & $4.112(a)$ & 0.160 & $3.810,4.438$ & 2.908 & 3.884 & 0.548 \\
\hline CL-NTC & 8.338 & 2.022 & $5.183,13.412$ & $6.512(b)$ & 0.260 & $6.020,7.043$ & 4.653 & 6.150 & 0.888 \\
\hline CL-TC & 6.821 & 1.786 & $4.083,11.396$ & $3.935(a)$ & 0.192 & $3.576,4.330$ & 2.196 & 3.664 & 0.688 \\
\hline UL-NTC & 5.957 & 1.480 & $3.660,9.696$ & $6.867(b)$ & 0.385 & $6.151,7.667$ & 4.170 & 6.365 & 1.258 \\
\hline UL-TC & 8.808 & 2.262 & $5.323,14.574$ & $4.210(\mathrm{a})$ & 0.158 & $3.910,4.532$ & 3.004 & 3.975 & 0.607 \\
\hline Chi-square $(\mathrm{Df}=5)$ & 1.838 & & & 157.525 & & & & & \\
\hline p-value & 0.871 & & & $<0.001$ & & & & & \\
\hline
\end{tabular}

"Same superscript letters in columns show no differences.

Table 2: Results of Weibull analysis, Wald tests and mean shear bond strength results (MPa). 


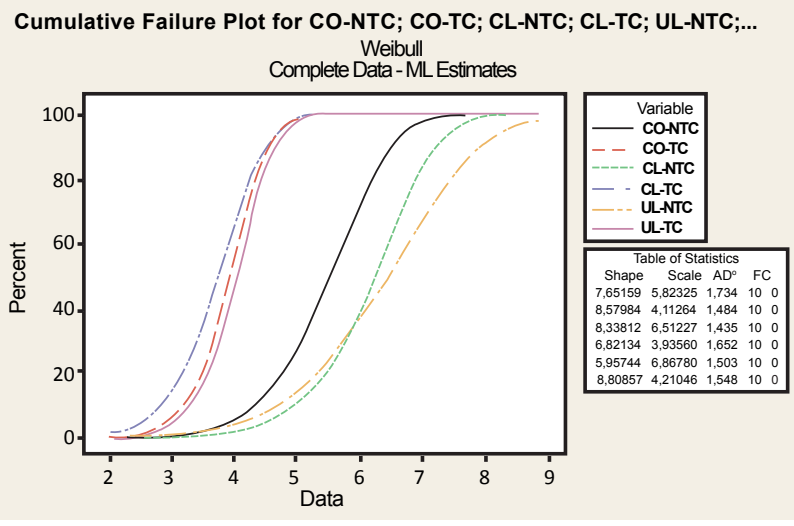

Figure 1: Weibull probability of failure curves for the shear bond strengths of resin composite to ceramic material in dry and aged conditions.

shear-bond strength data $\left(\sigma_{0}\right)(\mathrm{p}<0.001)$ (Table 2). According to the $95 \%$ confidence interval results, thermal cycling significantly affected the bond strength results. After the aging condition, bond strength results decreased with respect to the non-thermal cycling groups. In dry and aged conditions, there were no statistically significant differences among CO, CL, and UL shear bond strength $\left(\sigma_{0}\right)$. However, in each condition, UL revealed the higher bond-strength values.

The mean and standard deviation of shear bond strength values of composite bonded to the ceramic are also shown in Table 2. The mean shear bond strength in MPa ranking from highest to lowest were as follows: UL-NTC (6.365 \pm 1.258$)$; CL-NTC $(6.15 \pm 0.888)$; CO-NTC (5.498 \pm 0.748$)$; UL-TC (3.975 \pm 0.607$) ; \mathrm{CO}-\mathrm{TC}(3.884 \pm 0.548) ; \mathrm{CL}-\mathrm{TC}$ $(3.664 \pm 0.688)$.

\section{Topographic analysis}

The effects of the surface treatments on Cerec porcelain were demonstrated in Figure 2. Figure 2A showed the effect of airborne particle abrasion with $50-\mu \mathrm{m} \mathrm{Al}_{2} \mathrm{O}_{3}$ particles, and Figure $2 \mathrm{~B}$ showed the silica coating with $30-\mu \mathrm{m} \mathrm{SiO}_{2}$ particles. Air abrasion of feldspathic ceramic surface produced a rougher surface than the silica-coated surface. The sand particle remnants could be seen in each figure. In addition, the effects of different etchants on the airborne-abraded feldspathic porcelain were shown in Figure 3. Figure 3A showed the effects of $40 \% \mathrm{H}_{3} \mathrm{PO}_{4}$, and Figure $3 \mathrm{~B}$ showed the $9 \%$ buffered HF acid on the porcelain surface. In both Figures $3 \mathrm{~A}$ and $3 \mathrm{~B}$, honeycomb-like surfaces could be seen. However, $9 \%$ buffered HF acid seemed more effective than the $40 \% \mathrm{H}_{3} \mathrm{PO}_{4}$ on the ceramic surface.

\section{Failure types}

Table 3 showed the failure types of ceramic repair materials in dry and aged conditions. In dry conditions, specimens treated with $\mathrm{CO}$ mainly demonstrated a mix failure type (80\%). In the CL group, mainly cohesive failure (70\%) was observed, and in the UL group, cohesive (50\%) and $\operatorname{mix}(50 \%)$ failures were observed. When observations were evaluated within failure type, visual and stereomicroscopic analysis demonstrated almost all mix and cohesive failures in dry conditions after all repair methods.

After aging conditions, all repair methods predominantly demonstrated a mixed failure type $(90 \%, 80 \%$, and $70 \%$ for CO, CL, and UL, respectively). When evaluated within failure type, mix failures $(80 \%)$ were seen, too.

\section{Discussion}

Porcelain can be repaired using porcelain repair systems without removal of the prosthesis. A direct repair option may be practical for

\begin{tabular}{|c|c|c|c|c|c|c|c|}
\hline & & & & \multicolumn{3}{|c|}{ FAILURE TYPE } & \multirow[b]{2}{*}{ Total } \\
\hline & & & & ADHESIVE & COHESIVE & Mix & \\
\hline \multirow[t]{12}{*}{ NTC } & MATERIAL & $\mathrm{CO}$ & Count & 0 & 2 & 8 & 10 \\
\hline & & & $\%$ within MATERIAL &, $0 \%$ & $20,0 \%$ & $80,0 \%$ & $100,0 \%$ \\
\hline & & & $\%$ within FAILURETYPE &, $0 \%$ & $14,3 \%$ & $53,3 \%$ & $33,3 \%$ \\
\hline & & $\mathrm{CL}$ & Count & 1 & 7 & 2 & 10 \\
\hline & & & $\%$ within MATERIAL & $10.0 \%$ & $70 \%$ & $20 \%$ & $100,0 \%$ \\
\hline & & & $\%$ within FAILURETYPE & $100 \%$ & $50 \%$ & $13,3 \%$ & $33,3 \%$ \\
\hline & & UL & Count & 0 & 5 & 5 & 10 \\
\hline & & & $\%$ within MATERIAL &, $0 \%$ & $50 \%$ & $50 \%$ & $100,0 \%$ \\
\hline & & & $\%$ within FAILURETYPE &, $0 \%$ & $35,7 \%$ & $33,3 \%$ & $33,3 \%$ \\
\hline & Total & & Count & 1 & 14 & 15 & 30 \\
\hline & & & $\%$ within MATERIAL & $3,3 \%$ & $46,7 \%$ & $50 \%$ & $100 \%$ \\
\hline & & & $\%$ within FAILURETYPE & $100 \%$ & $100 \%$ & $100 \%$ & $100 \%$ \\
\hline \multirow[t]{12}{*}{ TC } & MATERIAL & $\mathrm{CO}$ & Count & 1 & 0 & 9 & 10 \\
\hline & & & $\%$ within MATERIAL & $10.0 \%$ &, $0 \%$ & $90,0 \%$ & $100,0 \%$ \\
\hline & & & $\%$ within FAILURETYPE & $100 \%$ &, $0 \%$ & $37,5 \%$ & $33,3 \%$ \\
\hline & & $\mathrm{CL}$ & Count & 0 & 2 & 8 & 10 \\
\hline & & & $\%$ within MATERIAL &, $0 \%$ & $20 \%$ & $80,0 \%$ & $100,0 \%$ \\
\hline & & & $\%$ within FAILURETYPE &, $0 \%$ & $40,0 \%$ & $33,3 \%$ & $33,3 \%$ \\
\hline & & UL & Count & 0 & 3 & 7 & 10 \\
\hline & & & $\%$ within MATERIAL &, $0 \%$ & $30,0 \%$ & $70,0 \%$ & $100,0 \%$ \\
\hline & & & $\%$ within FAILURETYPE &, $0 \%$ & $60,0 \%$ & $29,2 \%$ & $33,3 \%$ \\
\hline & Total & & Count & 1 & 5 & 24 & 30 \\
\hline & & & $\%$ within MATERIAL & $3,3 \%$ & $16,7 \%$ & $80,0 \%$ & $100,0 \%$ \\
\hline & & & $\%$ within FAILURETYPE & $100,0 \%$ & $100,0 \%$ & $100,0 \%$ & $100,0 \%$ \\
\hline
\end{tabular}

Table 3: Failure types of ceramic repair kits in dry and aged conditions. 
both the clinicians and the patients as an interim solution. This in vitro investigation compared the shear bond strengths of three different porcelain repair systems in dry and aged conditions. In the present study, three repair kits were evaluated according to the manufacturer's instructions.

Some authors [15-17] reported that a combination of airborne particle abrasion with $\mathrm{Al}_{2} \mathrm{O}_{3}$ and etching with $\mathrm{HF}$ acid yielded higher bond strength values to silica-based ceramics (feldspathic, Empress I, lithium disilicate-based ceramics), and others $[18,19]$ reported that high-strength ceramics (alumina, zirconia ceramics) treated with a silica-coating technique yielded the highest bond strength values to a composite resin. In this study feldspathic porcelain was used for repairing. The systems used in this study relied on chemical adhesion (silane-coupling agents) as well as on mechanical retention (roughened surfaces). Tribochemical silica coating (in CO group) and air-abrasion methods (in CL and UL groups) were used to obtain mechanical retention on porcelain surfaces prior to porcelain repairing. SEM examinations of different pretreatments revealed that airborne-abraded porcelain surfaces were better than silica-coated surfaces (Figures 2A and $2 \mathrm{~B})$.

It is known that airborne particle abrasion and HF selectively dissolve the weaker glass phase and create retentive surfaces. The porous irregular surface facilitates the penetration of resin into the microretentions of the treated ceramic surfaces [12]. In our study, both $\mathrm{CL}$ and UL repair kits were based on acid applications. While CL repair was based on $40 \% \mathrm{H}_{3} \mathrm{PO}_{4}$ acid, UL repair was based on $9 \%$ buffered HF acid. In addition, SEM photomicrographs of different etchants on Cerec porcelain revealed that $9 \%$-buffered HF acid demonstrated more microretentive surfaces than the $40 \% \mathrm{H}_{3} \mathrm{PO}_{4}$ acid sample (Figures $3 \mathrm{~A}$ and $3 \mathrm{~B}$ ). However, the application times of these acids were different from each other. In this study, although the surface roughness of the substrate after the roughening methods was not evaluated, it could be anticipated that airborne particle abrasion with HF acid application in the UL repair group better served the bond-strength results. In our study, this fact could be interpreted by evaluating the SEM micrographs and bond-strength data (Figure 3 and Table 2).

The distribution of data obtained from the strength test related to porcelains is not normal [20,21]. Because ceramics and dental composites exhibit a brittle fracture mode, expressing the mechanical behavior of a brittle material as a single mean value may not sufficient to indicate the true strength and reliability of the bond strength. The Weibull analysis of bond strength data, which related the probability

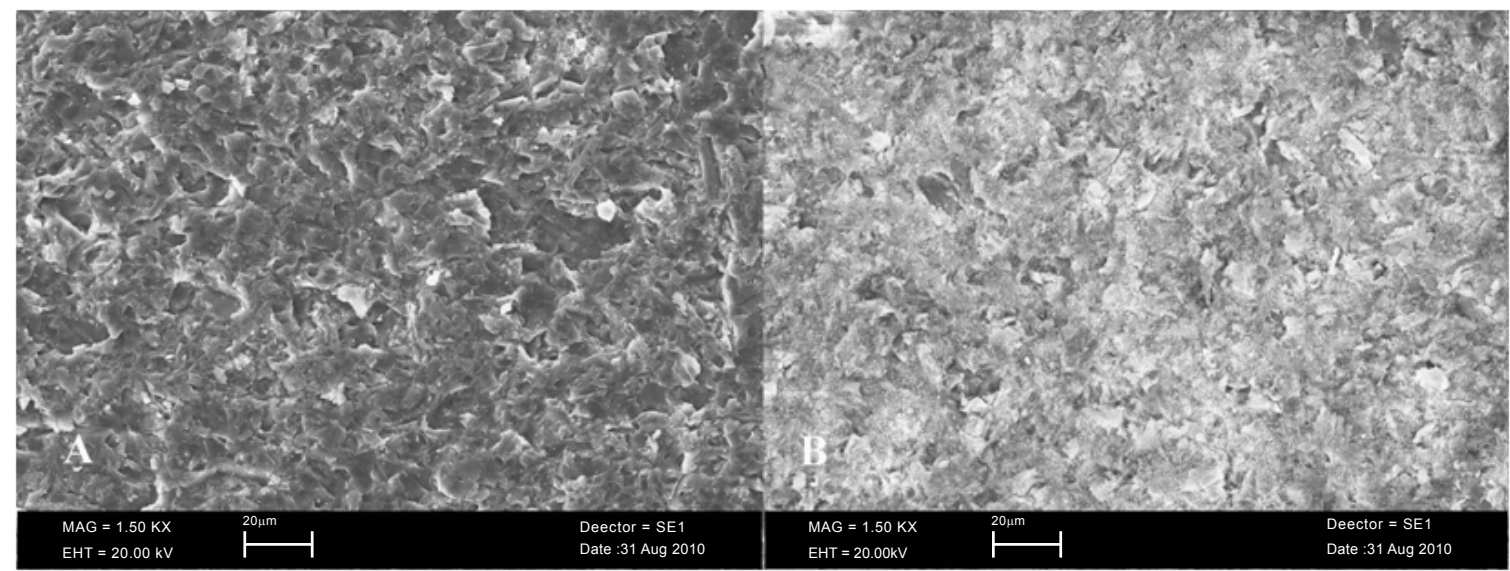

Figure 2: SEM micrographs of conditioned ceramic surfaces. (A) Airborne particle abrasion with $50 \mu \mathrm{m} \mathrm{Al}_{2} \mathrm{O}_{3}$ particles. (B) Silica coating with $30 \mu \mathrm{m}$ SiO ${ }_{2}$ particles (original magnification $1.50 \mathrm{KX})$.

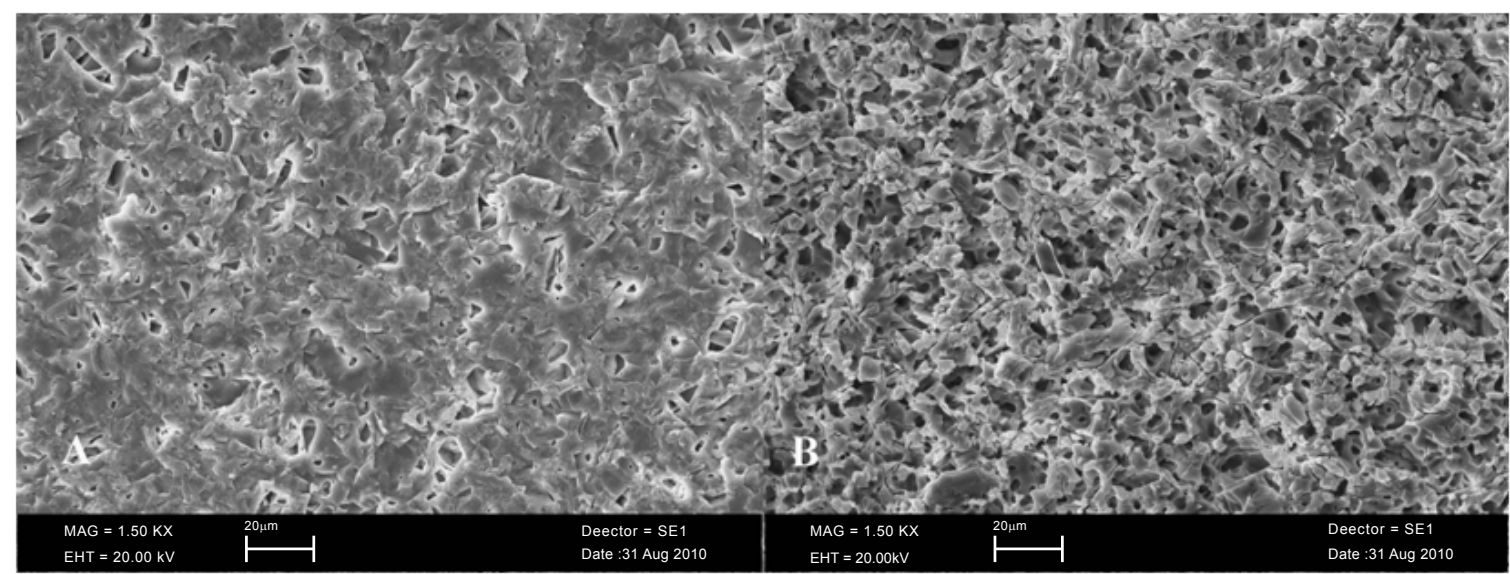

Figure 3: SEM micrographs of different etchants on $50 \mu \mathrm{m}$ airborne particle abraded feldspathic porcelain surface. (A) Etching with $40 \% \mathrm{H}_{3} \mathrm{PO}{ }_{4}$ acid. (B) Etching with $9 \%$ buffered HF acid (original magnification $1.50 \mathrm{KX}$ ). 
of failure at a given stress level, is a more powerful method than using only the mean value [22]. In addition, the failure probability of materials at any stress level could also be predicted. Due to these reasons, Weibull analysis was used for the statistical analysis to evaluate the bond-strength data.

In dry conditions, according to Wald tests and $95 \%$ confidence intervals results, there were no significant differences among the three repair kits' characteristic bond strength values $\left(\sigma_{0}\right)$. However, UL seemed to reveal the highest characteristic bond-strength value.

Van der Vyver et al. [23] compared the shear-bond strength of five porcelain repair systems on Cerec porcelain. They found the best results with the Ultradent repair kit. Similarly, in our study, Ultradent seemed to reveal the highest characteristic bond-strength $\left(\sigma_{0}\right)$ data in dry and aged conditions.

Thermocycling and water storage in vitro is a common method of testing dental materials to establish their suitability for in vivo use $[24,25]$. It has been proven that water, owing to its small molecular size and high molar concentration, can penetrate into nanometersize free-volume spaces between polymer chains that are capable of hydrogen bonding, resulting in a decrease in thermal stability [26]. In this study, the decrease in bond strength for all repair systems from dry to aged conditions could be explained by the water uptake between the interlocking areas. Similar to these studies [24,25], in our study, according to Wald tests and $95 \%$ confidence intervals, characteristic bond strength $\left(\sigma_{0}\right)$ significantly decreased after thermal cycling $(\mathrm{P}<$ 0.001) (Table 2). Therefore, these results verified the hypothesis. When three repair kits were compared with each other in aged conditions, no statistically significant differences were found. However, thought not found to be statistically significant, Ultradent repair seemed to have the highest characteristic bond-strength $\left(\sigma_{0}\right)$ value.

The quality of the bond should not be evaluated based on bondstrength data alone. The mode of failure could provide important information about the bond-strength results. In dry conditions, almost all mix and cohesive failures were seen. However, for all three repair systems, mixed failure types increased after aging conditions. This might be due to the chemical bond between the ceramic and composite system and the effect of the aging condition. These findings were consistent with previous studies [16,24].

Many methods of measuring the in vitro bond strength of porcelain repair systems have been described. These include shear [27-29], microtensile [24,25], and microshear [16] bond-strength tests. One of the most commonly employed is the shear bond-strength test [30]. Although it was reported that this test could create non-uniform stress distribution at the bonding interface, this test is often used because of simplicity and ease of application [31]. Therefore, this test method was performed in this study.

This study had some limitations. In this study, the application time and concentrations of acids were different. However, this study was conducted according to the manufacturer's instructions. In further studies, these factors should be controlled. In addition, thermal cycling was used as an aging procedure. To better simulate a clinical environment, thermal cycling should be combined with cyclic fatigue. The in vivo bonding ability of these systems should also be tested.

The findings of this study should be carefully considered for clinical application, and bond-strength durability of these repair systems should also be evaluated after long-term aging procedures. In addition, though not found statistically significant, combining acid etching and silane application is an appropriate selection for feldspathic porcelain repairing. However, further investigations are required to know which conditioning methods play the crucial role in long-term adhesion of porcelain-composite bonding.

Within the limitations of this study, the following conclusions were drawn:

1. Thermal cycling had a significant effect on the bond strength of three repair kits. Characteristic shear-bond strengths $\left(\sigma_{0}\right)$ of three repair kits decreased after thermal cycling.

2. When bond-strength results and failure types were evaluated together, each of three systems could be recommended. However, though not found statistically significant, the UL repair kit seemed to show a higher characteristic shear-bond strength $\left(\sigma_{0}\right)$ value than the other repair kits.

\section{Acknowledgements}

The authors thank Assistant Professor Mustafa Semiz (Department of Statistics, Selcuk Unıversity) for the statistical analysis and Dr.Ihsan Aksit (Erciyes University Technology Research and Application Center) for the scanning electron microscopy analysis.

\section{References}

1. Liu PR, Essig ME (2008) Panorama of dental CAD/CAM restorative systems Compend Contin Educ Dent 29: 486-488.

2. Conrad HJ, Seong WJ, Pesun IJ (2007) Current ceramic materials and systems with clinical recommendations: a systematic review. J Prosthet Dent 98: 389404.

3. Bindl A, Mörmann WH (2003) Clinical and SEM evaluation of all-ceramic chairside CAD/CAM-generated partial crowns. Eur J Oral Sci 111: 163-169.

4. Bindl A, Mörmann WH (2004) Survival rate of mono-ceramic and ceramic-core CAD/CAM-generated anterior crowns over 2-5 years. Eur J Oral Sci 112: 197 204

5. Peumans M, De Munck J, Fieuws S, Lambrechts P, Vanherle G, et al. (2004) A prospective ten-year clinical trial of porcelain veneers. J Adhes Dent 6: 65-76.

6. Marquardt P, Strub JR (2006) Survival rates of IPS empress 2 all-ceramic crowns and fixed partial dentures: results of a 5-year prospective clinical study. Quintessence Int 37: 253-259.

7. Latta MA, Barkmeier WW (2000) Approaches for intraoral repair of ceramic restorations. Compend Contin Educ Dent 21: 635-644.

8. Edelhoff D, Marx R, Spiekermann H, Yildirim M (2001) Clinical use of an intraoral silicoating technique. J Esthet Restor Dent 13: 350-356.

9. Matinlinna JP, Vallittu PK (2007) Bonding of resin composites to etchable ceramic surfaces - an insight review of the chemical aspects on surface conditioning. J Oral Rehabil 34: 622-630.

10. Alex G (2008) Preparing porcelain surfaces for optimal bonding. Compend Contin Educ Dent 29: 324-335.

11. Matinlinna JP, Lassila LV, Ozcan M, Yli-Urpo A, Vallittu PK (2004) An introduction to silanes and their clinical applications in dentistry. Int J Prosthodont 17: 155-164.

12. Ozcan M, Vallittu PK (2003) Effect of surface conditioning methods on the bond strength of luting cement to ceramics. Dent Mater 19: 725-731.

13. Ozcan M (2002) The use of chairside silica coating for different dental applications: a clinical report. J Prosthet Dent 87: 469-472.

14. Bona AD, Anusavice KJ, DeHoff PH (2003) Weibull analysis and flexura strength of hot-pressed core and veneered ceramic structures. Dent Mater 19 662-669. 
Citation: Subaşı G, İnan Ö (2012) Shear Bond Strength of Three Porcelain Repair Systems on Porcelain in Dry and Aged Conditions. Dentistry 2:119. doi:10.4172/2161-1122.1000119

15. Kim BK, Bae HE, Shim JS, Lee KW (2005) The influence of ceramic surface treatments on the tensile bond strength of composite resin to all-ceramic coping materials. J Prosthet Dent 94: 357-362.

16. Panah FG, Rezai SM, Ahmadian L (2008) The influence of ceramic surface treatments on the micro-shear bond strength of composite resin to IPS Empress 2. J Prosthodont 17: 409-414

17. Oh WS, Shen C (2003) Effect of surface topography on the bond strength of a composite to three different types of ceramic. J Prosthet Dent 90: 241-246.

18. Attia A (2010) Influence of surface treatment and cyclic loading on the durability of repaired all-ceramic crowns. J Appl Oral Sci 18: 194-200.

19. Della Bona A, Borba M, Benetti P, Cecchetti D (2007) Effect of surface treatments on the bond strength of a zirconia-reinforced ceramic to composite resin. Braz Oral Res 21: 10-15.

20. Kern M, Thompson VP (1995) Bonding to glass infiltrated alumina ceramic: adhesive methods and their durability. J Prosthet Dent 73: 240-249.

21. Kern M, Wegner SM (1998) Bonding to zirconia ceramic: adhesion methods and their durability. Dent Mater 14: 64-71.

22. Viwattanatipa N, Jermwiwatkul W, Chintavalakorn R, Kanchanavasita W (2010) Weibull analysis of bond strength of orthodontic buccal tubes bonded to resin composite surface with various techniques. Orthodontic Waves 69: 66-74.

23. Van der Vyver PJ, de Wet FA, Botha SJ (2005) Shear bond strength of five porcelain repair systems on cerec porcelain. SADJ 60: 196-198, 200.
24. Goia TS, Leite FP, Valandro LF, Ozcan M, Bottino MA (2006) Repair bond strength of a resin composite to alumina-reinforced feldspathic ceramic. Int $J$ Prosthodont 19: 400-402

25. Ozcan M, Valandro LF, Amaral R, Leite F, Bottino MA (2009) Bond strength durability of a resin composite on a reinforced ceramic using various repair systems. Dent Mater 25: 1477-1483.

26. Peumans $M$, Van Meerbeek $B$, Lambrechts $P$, Vuylsteke-Wauters $M$, Vanherle $\mathrm{G}$ (1998) Five-year clinical perfomance of porcelain veneers. Quintessence Int 29: 211-221.

27. Güler AU, Yilmaz F, Yenisey M, Güler E, Ural C (2006) Effect of acid etching time and a self-etching adhesive on the shear bond strength of composite resin to porcelain. J Adhes Dent 8: 21-25.

28. Knight JS, Holmes JR, Bradford H, Lawson C (2003) Shear bond strengths of composite bonded to porcelain using porcelain repair systems. Am J Dent 16 252-254.

29. Kumbuloglu O, User A, Toksavul S, Vallittu PK (2003) Intra-oral adhesive systems for ceramic repairs: a comparison. Acta Odontol Scand 61: 268-272.

30. Della Bona A, van Noort R (1995) Shear vs. tensile bond strength of resin composite bonded to ceramic. J Dent Res 74: 1591-1596.

31. Van Noort R, Noroozi S, Howard IC, Cardew G (1989) A critique of bond strength measurements. J Dent 17: 61-67. 